\title{
O lixo no discurso jornalístico da cidade de Cáceres-MT: uma questão para análise de discurso.
}

\section{La basura en el discurso periodístico de la ciudad de Cáceres-MT: una} cuestión para el análisis de discurso.

\section{Garbage in the journalistic discourse of the city of Cáceres-MT: a question}

for discourse analysis.

\author{
Renata Carneiro Lemes ${ }^{1}$
}

\begin{abstract}
RESUMO
Com base na teoria da análise de discurso, este artigo, procura analisar o discurso ambiental, a partir da temática sobre o lixo, nos jornais de circulação da cidade de Cáceres-MT. O discurso ambiental pode ser analisado por uma multiplicidade de materiais e de práticas de linguagem como leis, publicidade, espaço citadino, etc. Por outro lado, nesse artigo, utilizamos como corpus de análise os jornais Expressão Notícia, Correio Cacerense, Diário de Cáceres que circularam na em Cáceres, localizada no Estado de Mato- Grosso. Depreende-se que o sentido do verbete lixo não é homogêneo, diferencia-se de acordo com as distintas formações discursivas presente no discurso jornalístico.
\end{abstract}

PALAVRAS-CHAVE: Discurso; Sentido; Mídia; Jornalismo; Resíduos sólidos.

\section{RESUMEN}

A partir de la teoría del análisis de discurso, este artículo, busca analizar el discurso ambiental, a partir de la temática sobre la basura, en los diarios de circulación de la ciudad de Cáceres-MT. El discurso ambiental puede ser analizado a partir de una multiplicidad de materiales y de prácticas de lenguaje como leyes, publicidad, espacio de la ciudad, etc. Por otro lado, en ese artículo, utilizamos como corpus de análisis los periódicos Expresión Noticia, Correio Cacerense, Diario de Cáceres que circularon en la ciudad de Cáceres, ubicada en el Estado de Mato Grosso. Parece que el significado de la entrada no es homogéneo, difiere según las diferentes formaciones discursivas presentes en el discurso periodístico.

PALABRAS CLAVE: Discurso; Sentido; Medios de comunicación; El periodismo; Residuos sólidos.

\begin{abstract}
Based on the theory of discourse analysis, this article seeks to analyze the environmental discourse, from the thematic about trash, in the circulation newspapers of the city of Cáceres-MT. Environmental discourse can be analyzed from a multiplicity of materials and language practices such as laws, publicity, city space, etc. On the other hand, in this article, we used as corpus of analysis the News Expression, Correio Cacerense, Diário de Cáceres newspapers that circulated in the city of Cáceres, located in the State of Mato Grosso. It seems that the meaning of entry into homogeneity differs according to the different discursive formations present in periodic discourse.
\end{abstract}

KEY WORDS: Discourse; Sense; Media; Journalism; solid waste.

\footnotetext{
${ }^{1}$ Doutoranda do Programa de pós- graduação em Linguística pela Universidade de Mato Grosso (UNEMAT), Campus Jane Vanini, Cáceres-MT, lemes.renata9@gmail.com.
} 


\section{Introdução}

Este artigo discute a questão ambiental, a partir da temática sobre o verbete lixo nos jornais de circulação na cidade de Cáceres localizada no Estado de Mato- Grosso nos anos de 2007, 2008, 2014 e 2018. Vale ressaltar que o discurso ambiental em jornais de circulação nas cidades localizadas no Estado de Mato Grosso tem um diferencial, por ter uma área considerada pela Constituição Federal de 1988, como área de preservação ambiental, Patrimônio Natural da Humanidade, o Pantanal. Esse discurso institucional alarga as discussões no sentido de compreender, pelas análises, como a questão ambiental, sobre o lixo, produz efeitos de sentido nos jornais de Cáceres-MT.

A partir de Silva (2016) compreende-se o espaço como uma materialidade política que corporifica a cidade, de modo que o ambiente está intrinsicamente atado ao espaço citadino. Ao produzir-se acúmulo de dejetos e poluição, queimadas e devastações, acarretará consequências dessas relações significativas no espaço urbano. Para a autora (op. cit.) os rios constituem corpo político do urbano, por serem utilizados, desde os primórdios da formação das mesmas, como meio de transporte, lazeres, produção de energia e escoamento de dejetos. Um caso de poluição de rio por dejetos em Cáceres-MT, conhecida como cidade turística, em que sua economia depende basicamente da saúde do Rio Paraguai. Na data de 14/10/2018 a ação da prefeitura, juntamente com 180 voluntários retirou do Rio Paraguai cerca de seis toneladas de lixo, os dejetos foram expostos na Praça Barão do Rio Branco como forma de conscientizar a população da importância de cuidar dos mananciais de água. Vejamos a imagem,

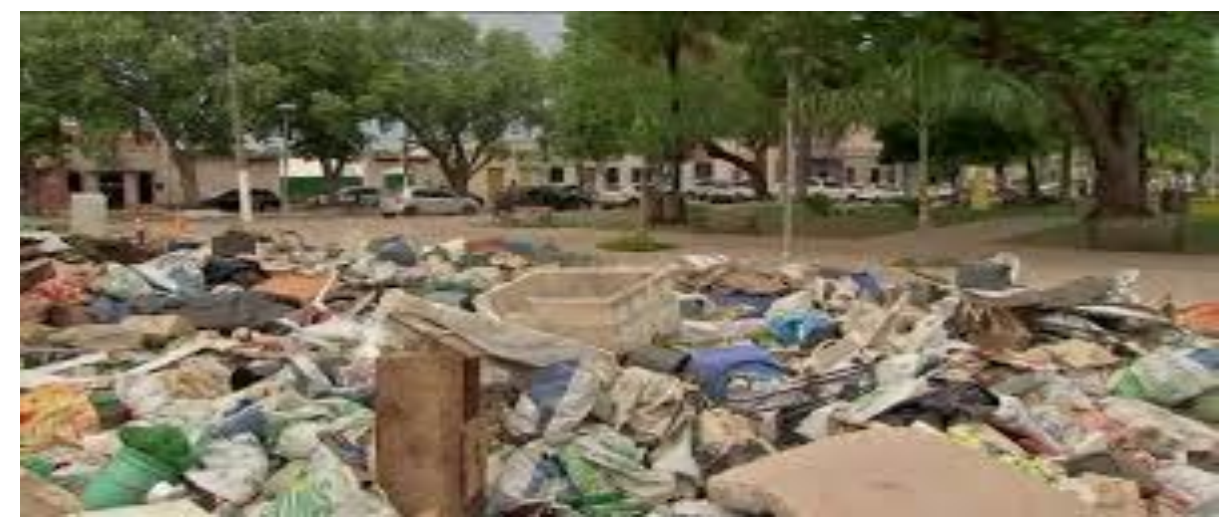

Figura 01 (Imagem da reportagem do Jornal Nacional em 14/10/2018. Visualizado em https://www.saibatudomt.com.br/2018/10/caceres-seis-toneladas-de-lixo-sao-retiradas-do-rio-paraguai-eexpostas-em-praca.html) 
Na imagem (Fig. 01) apresenta a ação da prefeitura de Cáceres-MT ao expor o lixo retirado do Rio Paraguai na Praça Barão do Rio Branco, no gesto é preciso levar em consideração, o discurso da conscientização e da preservação do Rio Paraguai, uma vez que muitos moradores, pescadores, visitantes, turistas pescam e jogam lixos nesse leito. Nessa relação entre o sujeito x natureza, é interessante observar a noção da não preservação do rio pela quantidade de dejetos retirados do Rio Paraguai. A ação da Prefeitura de Cáceres-MT em expor os lixos em praça pública, discursivamente, mobiliza gestos de interpretação. O gesto da Prefeitura espera-se que produza efeito de sentido, dessa ação, na posição sujeito morador de Cáceres, isto é efeito da conscientização ambiental.

Depreende que na cidade à medida que a população sofre a interpelação da importância da qualidade de vida e da preservação do ecossistema a temática ambiental emerge em diferentes materialidades, de maneira que tem sido tema de debates e preocupação, e consecutivamente, interesses das organizações Não-Governamentais (ONG's), cidades, Prefeituras Municipais, do Estado, de escolas mediante a inclusão da temática ambiental nos PCNs- Parâmetro Curricular Nacional e de matérias de jornalística.

O jornal coloca-se como um meio tecnológico de escrita, de produção de diferentes textos, que tem uma circularidade, com poder de fazer dizer diferentes temáticas, que por vezes têm grande repercussão na cidade. Desse modo, considerando que "a materialidade específica da ideologia é o discurso e a materialidade específica do discurso é a língua" (ORLANDI, 1999, p.17), interessam-nos compreender como o discurso jornalístico, entendido como materialidade significante da língua, atravessado por diferentes posições ideológicas, condições de produção, permite questionamento, gestos de interpretação sobre a temática do lixo.

O jornal escrito ou verbal na cidade tornou-se um dos principais fornecedores de informação, formador de opinião sobre distintos acontecimentos, definido como "um elemento simbólico do cotidiano urbano, e remete aos seus modos de circulação" (SILVA, 2016, p. 1066), como é o caso de vendas de jornais em bancas e entrega em residências. Na posição de estudioso da língua, pelo aporte teórico da Análise do Discurso, tomamos o jornal como àquele que faz veicular uma matéria de importância, neste caso, o discurso ambiental, que tematiza o produto do consumo: o lixo. Este de certa forma tornou-se preocupação mundial, dada o efeito de lixo na sociedade. A temática sobre o lixo tornou-se ao fio do discurso ecológico algo que perpassa o poder local, ou seja, reverbera sentidos no aspecto global. Como tratá-lo? A problemática do lixo sofre a interpelação de distintos segmentos da 
sociedade e vem sendo cada vez mais discutida em eventos, assinaturas de países que diz da relação do homem com o mundo.

Conforme Silva (2016) o acúmulo do capitalismo tem fortalecido constantemente, e tem como consequência outra acumulação, a do lixo, como "partes significante das práticas de consumo na sociedade" (SILVA, 2016, p. 140), e para isso tem demandado estratégias de aprendizagem, educação ambiental de investimento em cooperativas que desenvolva mecanismo de conscientização na sociedade, como o a Lei de Resíduos Sólidos $\mathrm{n}^{\circ}$ 12.305/2010 convocada pelo Estado aos segmentos da sociedade para uma reescrita da regularidade jurídica, que norteia sobre o tratamento dos resíduos sólidos, tendo como porta voz o Ministério do Meio Ambiente delega aos municípios que se instituam aterros sanitários, em um tempo determinado. Conforme dispõem a Lei 12.305/2010 de resíduos sólidos no Art. 175 ,

\begin{abstract}
As pessoas físicas ou jurídicas são responsáveis pela implementação e operacionalização integral do plano de gerenciamento de resíduos sólidos aprovado pelo órgão competente na forma do art. 24 . O plano de gerenciamento de resíduos sólidos é parte integrante do processo de licenciamento ambiental do empreendimento ou atividade pelo órgão competente do Sisnama (art.24).
\end{abstract}

A Lei de Resíduos Sólidos citada, a representatividade simbólica, mostra uma determinação política em relação ao social em que os dispositivos de coerção tenham efeitos nas práticas do sujeito com o ambiente, na qual o não cumprimento sobre o que prevê a Lei em relação à questão ambiental, significa sanções, obrigatoriedade de recuperação e manutenção do território ${ }^{2}$. A perspectiva do aterro sanitário e de conter possíveis contaminações, tais como os mananciais, rios, lagos, animais e a saúde humana, funciona como uma forma de organização e "urbanização da cidade" 3 . Assim, essa forma de relação sujeito e espaço, de organização política, chama a atenção para as relações de força de trabalho, o planejamento urbano, saneamento básico, o tratamento do lixo.

Abaixo, trata-se de um discurso transcrito em uma placa, localizado as margens do Rio Paraguai (Cáceres), em frete a um restaurante. No dizer, o locutor Prefeitura de Cáceres enuncia a seu interlocutor moradores da cidade. O sujeito cacerense está sendo convocado como o responsável pela limpeza e conservação do ambiente, pela venda da imagem do local para a visita do turista.

\footnotetext{
${ }^{2}$ Ver Motta (2012) Artigo A escrituração do pantanal no discurso ambiental.

${ }^{3}$ Silva (2011)Artigo .
} 


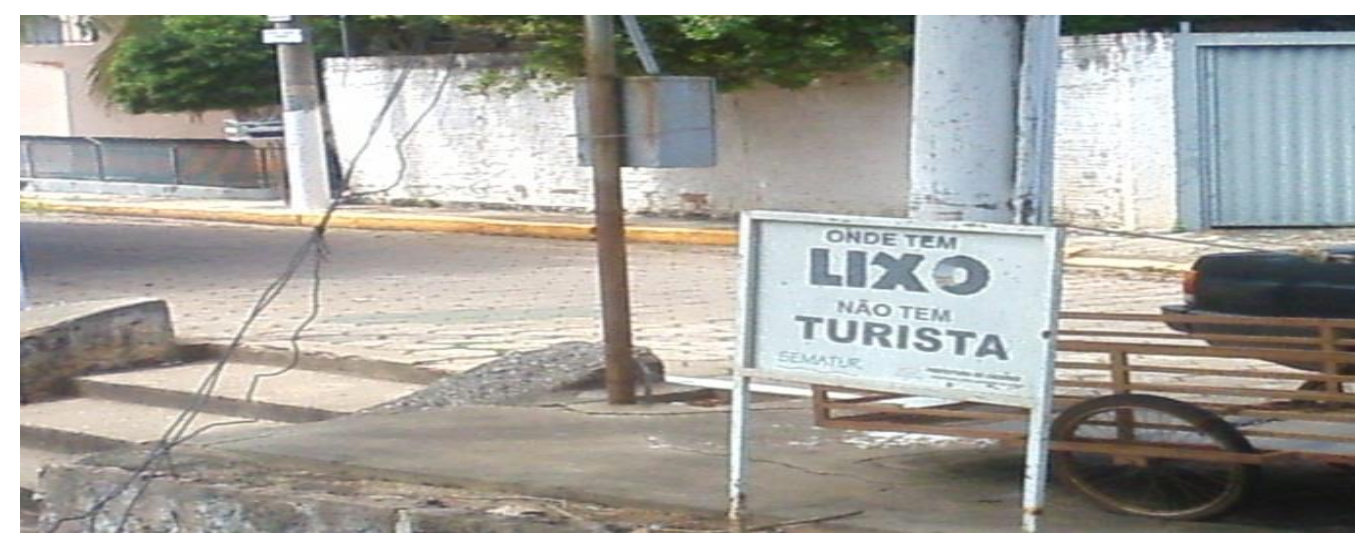

Figura 02 (Foto tirada de uma placa localizada as margens do Rio Paraguai em Cáceres-MT).

Na placa, a formulação "onde tem lixo não tem turista", exposta no espaço público urbano, tem o seu sentido instituído, organizado que reverbera sentidos à cidade ribeirinha, que por sua vez, é significada como um espaço para o turismo. Afinal, o espaço é limpo de lixos para os turistas e não para os moradores, pois onde não tem turista não haverá lucros econômicos, uma vez que o turismo é uma das fontes econômica da localidade. Na placa, observa-se que dois verbetes estão em letras maiores em suas relações com as paráfrases “onde tem x não tem". Os verbetes LIXO x TURISTA estão em sentido de oposição, confronto ideológico, já que onde houver lixo não haverá turista. Desse modo, há um gesto político citadino que se instaura no texto e faz menção significativa à cidade, como memória de um espaço econômico do/para o turismo. A memória, aqui, é pensada em relação ao discurso, àquilo que já foi dito em determinadas condições e que inconscientemente é retomada na formação do divisível, funcionando como um pré-construído. "O saber discursivo que torna possível todo dizer e que retorna sob a forma do pré-construído, o já dito que está na base do divisível, sustentando cada tomada da palavra" (ORLANDI, 1999:31). Na placa há uma contradição em funcionamento no discurso em face a questão do ambiente. Há posições antagônicas entre turistas x moradores cada qual com a sua forma distintiva de ser, de sobreviver, de viver. Porém, esse eixo nos textos em análise tem um mesmo que os atravessa - o lixo.

\section{Os sentidos de lixo em diferentes formações discursivas dos jornais de Cáceres-MT}

No recorte abaixo, a linguagem midiática toca a relação homem e natureza pela matéria veiculada, no social, que entrecruza a linguagem verbal e a não verbal sobre a questão do lixo. Em destaque a formulação "Catadores se alimentam de restos de comida no lixão" 
seguida da imagem não verbal, (fig. 01) $)^{4}$ enuncia ao sujeito leitor um flagrante do cotidiano em que o sujeito pela própria questão de sobrevivência, ele se assujeita a consumir o que a cidade estratifica como aquilo que não tem valor a priori. A expressão a priori já enuncia um a posteriori que faz emergir questões do urbano. Homens desempregados, questões de saúde, educação, planos políticos urbanísticos de tratamento da coleta do lixo. Leiamos.

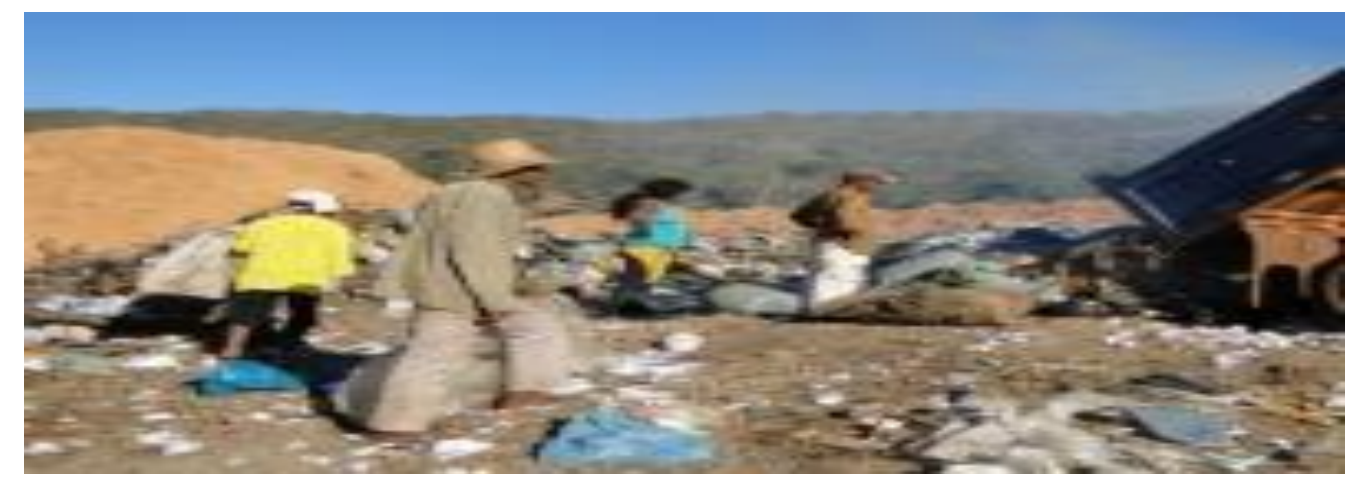

Figura 02 (Imagem publicada pelo jornal Expressão Notícias, de Cáceres/MT domingo 16/02/2014).

Catadores se alimentam de restos de comida no lixão

Informações obtidas pelo Ministério Público dão conta que, inúmeras famílias de catadores alimentam de restos de comida encontradas no local do córrego da Peraputanga [...] Moradores do local informam que, além de não consumir a água do córrego, alguns estão inserindo hipoclorito de sódio nos locais onde o gado bebe [...](grifo nosso). (Expressão Notícias, Cáceres/MT domingo 16/02/2014).

A matéria jornalística, produzida pelo jornal de Cáceres/MT, coloca em relevo a posição sujeito-catador e poder público em relação às condições de vida humana e o ambiente. Os lixos, os detritos, na localidade, no texto jornalístico, permitem gestos de leitura, produzem questionamentos entre as diferentes formações discursivas que entrecruzam o verbal e o não verbal que diz dos efeitos da degradação ambiental e humana. Pêcheux (1975, p.166) define formação discursiva "como um elemento suscetível de intervir como uma força confrontada a outras forças, dentro da conjuntura ideológica característica de uma formação social em um movimento dado", podendo ser uma ou mais formações discursivas interligadas. O sujeito se constitui no interior de uma formação discursiva, e a relação que esse sujeito estabelece entre as várias formações discursivas é constitutiva de cada sujeito.

Observamos que matéria jornalística se trata do córrego denominado Peraputanga, o nome provêm de um peixe de água doce, bem natural em que homens e animais dependem para sobreviver. Se de um lado, a água do córrego não serve para o consumo humano devido 
ao chorume do lixão e que animais a consomem a base de "hipoclorito de sódio", de outro lado, as informações para o Ministério Público é que famílias de catadores têm no lixão, o alimento, ainda que provindos de descartes, de restos de comida.

No jornal utiliza-se da linguagem: verbal e não verbal, permitindo criar diferentes gestos de leitura. O texto verbal é configurado pela sua forma escrita, quanto ao texto não verbal constituem-se por imagens, cores, desenhos. Analisando na forma significante não verbais são "os famosos implícitos, que estão ausentes por sua presença” (ORLANDI, 2010, p. 52). Para Orlandi,

O sentido tem uma materialidade própria, ou melhor, ele precisa de uma matéria específica para significar. Ele não significa de qualquer maneira. Entre as determinações - as condições de produção de qualquer discurso - está a da própria materialidade simbólica: o signo verbal, o traço, a sonoridade, a imagem etc., e a sua consistência significativa. (1995, p.39).

Depreende, nesse caso, que o jornal utiliza da materialidade do discurso não verbal como uma forma de transmitir o sentido da "veracidade" ao acontecimento ocorrido, essa forma de legitimar a notícia, submete o leitor ao efeito da evidência do sentido na literalidade, proposto pelo noticiado, impossibilitando o leitor (re) construir sentido outros, entretanto interpretar o discurso resulta de uma relação entre leitor/texto com os fatores sócio-histórico ideológicos, mais ainda, "a palavra do nosso cotidiano já chegam até nós carregadas de sentidos" (ORLANDI, 1999, p.20), podendo o sentido poder a vir ser outro.

Há uma ideologia que da comunicação social que faz com que se use a mídia verbalmente, Isto é de modo que outra linguagem que constitui a mídia não funcione sem o verbal. Para nós não é assim, isto é um efeito. A mídia tem seu domínio específico de significância e o verbal não é sobre determinante, quando restituímos a mídia a esse seu domínio próprio. (ORLANDI,1999, p.42).

Na matéria publicada pelo jornal, o verbal, produz o efeito da homogeneidade do não verbal, como se o texto verbal funcionasse como uma cópia, de modo que mascaram/silenciam outras possibilidades de interpretação, isto é, tudo se interpreta da mesma forma. Assim ocorre uma unicidade/uniformidade nos sentidos de lixo, o efeito da literalidade na linguagem jornalística. Com isso, a linguagem verbal sobre o não verbal silencia outras formas de (re) significar o lixo, assim analisar o lixo no discurso jornalístico significa considerar o silêncio que lhe constitui e que se diferencia conforme as distintas formações discursivas. 
Porque o sentido não é um é muitos. E isto está dito na Análise de discurso, quando se define o dizível pelo conjunto de diferentes formações discursivas que se põem em jogo em cada gesto de dizer. Sendo o silencio um dos componentes das relações do sujeito com as relações discursivas, ele sujeito percorre diferentes (formações discursivas) a não ser que aí intervenha a censura. O caráter contínuo do silêncio permite ao sujeito se mover nas significações, percorre sentidos (ORLANDI, 1995, p.38).

Dessa forma, a imagem publicada pelo jornal Expressão Notícia da cidade de Cáceres produz significância, dando a possibilidade de o sentido vir a ser outro, portanto, o texto não verbal, veiculado no jornal, silencia sentidos de contradição da realidade social, diante de pessoas que entrecruzam os detritos, com gesto quase sempre com as mãos na cintura, observando expectativamente o caminhão que descarrega seus detritos, como de alguém que procura algo que lhe tem como sobrevivência. Nota-se que os rostos dos catadores são imperceptíveis, reverberando sentidos da invisibilidade social, já que os rostos caracterizam a identidade do sujeito/catador.

No enunciado "inúmeras famílias de catadores alimentam de restos de comida encontradas no local do córrego da Peraputanga", a posição sujeito interpelado no texto não são os catadores no lead, mas as famílias dos catadores que se alimentam dos detritos. Em seguida, não são as condições precárias dos sujeitos catadores que tem importância, mas a posição sujeito "moradores do local” que não consomem a água do córrego, devido à posição sujeito agropecuarista, apresentado pelo pronome indefinido "alguns", inserir hipoclorito de sódio nos locais do córrego onde o gado bebe.

Desse modo, no Jornal Expressão Notícia (16/ 02/2014) o sentido de "lixo" é (re) significado por diferentes posições sujeito ideológico, como "meio de sobrevivência", levando em consideração que é do lixo que os catadores citados retiram seus sustentos ou alimentação. Em decorrência dessa diferença de sujeito, que estão separados por suas formações discursivas e ideológicas, os sentidos dados ao lixo são determinados pela posição do sujeito/catador.

\subsection{Recorte: Charreteiros e caçambas ajudam a poluir}

No recorte abaixo, em que recebe a lead "Charreteiros e caçambas ajudam a poluir", pode-se observar, a princípio, que a formulação chama atenção para a posição sujeito o charreteiro e o caçambeiro ao editar no título da matéria que estes ajudam a poluir. O jogo discursivo de que se vale a linguagem jornalística, no texto, ao mobilizar no discurso o verbo 
ajudar, conjugado na $3^{\mathrm{a}}$ pessoa do plural, chama para a leitura da matéria. Por sua vez, a lead torna-se significativo na produção do sentido, remetendo ao que Pêcheux (1995) diz que o sentido não esta na palavra, mas nas diferentes formações ideológicas que permitem as diferentes formações discursivas. Leiamos.

[...] jogar lixo na rua é uma questão cultural, que independe inclusive da coleta realizada pela prefeitura $[\ldots]$ São pelo menos 150 charreteiros que vivem desse circulo vicioso de poluição; $[\ldots]$ Para Capistrano, o comportamento reflete em parte a preguiça, pois ir até o cesto de lixo armazenar os produtos gera mais trabalho [...]é mais fácil cobrar do outro que trazer para si a responsabilidade...A cidadania precisa amadurecer[...] (grifo nosso).

(Correio Cacerense, 16 de setembro de 2007)

No enunciado "jogar lixo na rua é uma questão cultural" diz da formação do cidadão, da relação cultural com o ambiente, funcionando como um modo de produção de sentidos sobre o "lixo", assim naturaliza-o, legitima seus sentidos, mascara as condições de produção que atravessa a temática do lixo na sociedade. O sentido de "lixo", no enunciado, vai sendo assim, cristalizado como hábitos, através de um processo cultural, o que reforça o efeito de apagamento da historicidade. Partindo das pistas deixadas por Pêcheux, Mariani (1998, p.45), define a cultura,

[...] como resultante de praticas dos sujeitos e entre sujeitos que remetem para um estado de coisas num determinado momento e em um determinado lugar em uma formação histórica; práticas vinculadas a maneira de se relacionar em sociedade. Ao mesmo tempo, são práticas não dissociadas dos modos sócio-históricos de produção, reprodução, resistências e transformação dos sentidos. Práticas expostas também à errância e à não totalidade dos processos de significação.

Nesse sentido, a cultura, assim como a ideologia, é constitutiva do sujeito, o lugar do político da/na sociedade, nesse sentido, ao significar o lixo como algo cultural, trata-se de um gesto de interpretação que faz parte do interdiscurso e que se configura como lugar da memória, do funcionando sobre o efeito elementar da ideologia como evidência. É a ideologia que gera a evidência e faz com que a prática de jogar lixo, adquira determinado sentido sobre a ilusão da transparência. Assim, no enunciado, o lixo (re) significa algo cultural, mostra na realidade uma censura, silenciando o efeito da memória que constitui as condições de produção. Para Orlandi (2010)

A memória, por sua vez, tem suas características, quando pensada em relação ao discurso. E nessa perspectiva, ela é tratada como interdiscurso. Este é definido como aquilo que fala antes, em outro lugar independentemente. Ou seja, é o que 
chamamos memória discursiva: o saber discursivo que torna possível todo dizer e que remota sob uma forma de pré-construído, o já dito que está na base do dizível, sustentando cada tomada de palavra. O interdiscurso disponibiliza dizeres que afetam o modo como o sujeito significa em uma situação discursiva dada. ( p.31).

Depreende se que a memória discursiva é compreendida como uma retomada, uma atualização, discursos-transversos que uma distinta leitura requer. Neste caso, o sentido de lixo é atravessado pela sua própria história, isto é sendo (re) significa não tão somente pelo seu estado atual, mas levando em consideração o seu histórico na humanidade. Desse modo, o sentido de lixo é atravessado pelo contexto sócio-histórico-ideológico enquanto o acontecimento social. Daí, a noção do sentido de lixo significando pela memória discursiva, diz respeito ao sujeito à historicidade que constitui a sua cultura.

No enunciado "A cidadania precisa amadurecer" diz sobre a prática de jogar lixo na rua que precisa "amadurecer", no sentido de mudança educacional que possa simbolizar um ato de "cidadania", isto é, a produção do lixo é algo do social, porém implica em uma postura do "cidadão" na sociedade, e é pela "cidadania" que nos garantimos como "sujeito" pela Constituição Federal. Esta significa possuir o conjunto de "direitos" e "deveres" que possibilita o sujeito participar ativamente da vida e do governo de seu povo. Conforme a Constituição Federal, Art.225

Todos têm direito ao meio ambiente ecologicamente equilibrado, bem de uso comum do povo e essencial à sadia qualidade de vida, impondo-se ao Poder Público e à coletividade o dever de defendê-lo e preservá-lo para os presentes e futuras gerações.

O discurso da constituição Federal se inscreve no discurso da "mundialização" dos cidadãos, através do uso do pronome indefinido "todos", que significa dizer que de acordo com a teoria da $\mathrm{AD}$, assumimos uma posição de "assujeitamento", somos sujeitos de direitos/deveres pela legislação, de modo que "todos" temos o direito de termos um ambiente "saudável", contanto que o "poder Público e à coletividade", retomando novamente o discurso da mundialização, tem o dever de cuidar e de preservá-lo. A respeito da Constituição de 1988, Motta (2012) argumenta que:

O Brasil se inscreve em uma formação ideológica dominante do capitalismo, da mundialização, no sentido de produzir uma lei que atravesse não somente o espaço nacional, mas que faça eco no espaço internacional. Há então uma pluralidade de sentidos que se significam no pronome indefinido "todos" e que reverbera sentidos sobre o acontecimento político (MOTTA, 2012, p.28). 
Desse modo, temos o direito de termos um ambiente "saudável", contanto que temos também o dever de cuidar e de preservá-lo. No dizer/fazer em relação ao espaço, o sujeito é atravessado ideologicamente pelas leis do Estado que trata do discurso jurídico e que chega à população pelos meios de comunicação ${ }^{5}$. Nesse relação, Orlandi $(2012$, p.167) diz que "já nascemos cidadãos, já a temos por direito" a prática da inadequação do lixo na sociedade, não implica na formação de cidadão, pois a cidadania é inata por direito, conforme a Constituição Federal no Art.225, mais uma vez, reforça a idéia da falta do Estado. Essa forma de qualificar o cidadão é uma tarefa do Estado e do Município por não cumprir suas obrigações e atribuir a responsabilidade ao cidadão. Então podemos observar que o discurso ecológico, de preservação mostram na realidade uma censura, algo silenciado, isto é não se joga lixo em qualquer lugar, se houver boa coleta de lixo. O que se pratica no enunciado é o discurso ecológico da falta social do Estado e do Município.

No dizer "São pelo menos 150 charreteiros que vivem desse círculo vicioso de poluição" considera-se, aqui, o lixo como um "círculo vicioso" em se tratando de vício nos limitemos em defini-lo como uma prática irresistível de mau hábito de consumo, seja ele de bebidas alcoólicas, drogas e cigarro, entretanto segundo a matéria do jornal "Correio Cacerense" o ato de poluir o meio ambiente também é caracterizada como vício, tão ilícito quanto os antes mencionados, que em muitas das vezes, não nos damos conta, pela naturalidade do fato.

No recorte do jornal "Correio Cacerense" (16/09/2007) o sentido de lixo é significado por diferentes formações discursivas e ideológicas que constituem o discurso em que se depreendem distintas posições institucionais ao qual o sujeito se inscreve. Isso significa dizer que é constituído por sujeitos ideológicos que significam pela integração entre o que se denomina de lixo na sociedade. O sentido de lixo é construído a partir de uma relação de integração entre lixo/sujeito, na qual o lixo é significado a partir do comportamento do indivíduo, como parte constituinte da produção, isto é como cultural, cidadania, preguiça e vício.

\footnotetext{
${ }^{5}$ Dissertação de Mestrado em 2003-Unicamp, publicado na Revista Revletras/GO.
} 


\title{
2.2 Recortes: Catadores já recebem ideia com bons olhos
}

No recorte abaixo, publicado pelo jornal "Diário de Cáceres", na qual recebe a formulação "Catadores já recebem ideia com bons olhos", diferentemente do recorte $\mathrm{n}^{\circ} 1$ e 2 , o sentido de lixo possui outra densidade semântica sobre seu uso na sociedade, sendo (re) significado com "bons olhos", isto é como ponto positivo. Se antes, no recorte $\mathrm{n}^{\mathrm{o}} 1$, era considerado como produto de alimento, para a posição sujeito catador, no recorte abaixo o lixo possui outra significância. Vejamos:

\begin{abstract}
O aumento da renda também é um ponto positivo avaliado por Santos, pois os catadores poderão ser remunerados pela prestação de serviços às prefeituras pela coleta, separação e reciclagem dos resíduos sólidos. Para Santos, não haverá mais desculpas para não fazer a coleta seletiva e reaproveitar os resíduos. Com o profissionalismo e boa vontade do poder público, só não vai reciclar quem não quiser, frisou [...] O lixão de Cáceres estava funcionando no local em caráter emergencial desde 2008. Além da baixa capacidade de receber dejetos, levantou suspeita que o liquido proveniente do lixo, o chorume, estaria se infiltrando nos lençóis freáticos a ponto de contaminar a água consumida pela população (grifo nosso). (Diário de Cáceres, domingo e segunda-feira, 08 e 09 de agosto de 2010).
\end{abstract}

No discurso "O aumento da renda também é um ponto positivo avaliado por Santos, pois os catadores poderão ser remunerados pela prestação de serviços às prefeituras pela coleta, separação e reciclagem dos resíduos sólidos", o lixo é configurado como remuneração, renda de trabalho, como as demais profissões, pela posição sujeito "catadores", através da reciclagem. Já no enunciado "Além da baixa capacidade de receber dejetos, levantou suspeita que o liquido proveniente do lixo, o chorume, estaria se infiltrando nos lençóis freáticos a ponto de contaminar a água consumida pela população". Vejamos o lixo sendo (re) significando pela posição do Estado como degradação do ambiente, isto é, "a expansão do discurso ambiental é proveniente do modo de interpelação do sujeito capitalista pela ideologia da preservação ambiental, que se significa em distintas posições-sujeito" (MOTTA, 2009, p.102) ${ }^{6}$. Portanto, o discurso sobre a conscientização ambiental é marcado, ideologicamente, pela posição sujeito que tem o lixo como fonte de trabalho, e pela posição sujeito que tem o lixo como poluição, que atinge os lençóis freáticos e causa a contaminação da água consumida pela população.

Nos jornais analisados, o sentido de lixo se diferencia conforme as diferentes formações discursivas do discurso jornalístico, e a sua relação com a ideologia. Conforme

\footnotetext{
${ }^{6}$ Ver Motta In "O ambiente no discurso jurídico da política pública urbana no Estado de Mato Grosso".
} 
Orlandi (1999, p.44) "as Palavras iguais podem significar diferentemente porque se inscrevem em formações discursivas diferentes". Por exemplo, a palavra "lixo" não significa o mesmo para a posição sujeito catador, carreteiro, morador etc. "O sujeito se constitui por uma interpelação- que se dá ideologicamente pela sua inscrição em uma formação discursiva" (ORLANDI, 1999, p.45). Por tanto todos esses usos se dão em condição de produção diferentes e podem ser referidos a diferentes formações discursivas.

Analisar o lixo no discurso jornalístico nos faz pensar na amplitude do reconhecimento da significação, desse modo como lugar de variadas interpretação, que permite compreender a língua sujeita a falhas, incompletude, isto é o sentido de lixo não se prende ao préestabelecido, da literalidade da palavra definida pelo dicionário e pelo jurídico, pois vária conforme as distintas posições sujeito que constitui as condições de produção, podendo (re) significar alimento, poluição, fonte de renda, objeto de descarte, produto de reciclagem etc. Nesse entendimento, os dizeres sobre o lixo não é tido isoladamente, é preciso que se tomem os contextos sócio-histórico-ideológicos que constituem as condições de produção do discurso.

A significação de lixo no discurso jornalístico coloca em cheque o jogo do funcionamento da linguagem, pois o sentido não provém da palavra em si, mas resulta da formação discursiva a que se remete que a produz no social, determinados ideologicamente, já que o sujeito é um sujeito ideológico. E através da ideologia se pode analisar na materialidade do discurso a significação.

\section{Considerações Finais}

Nesse artigo, analisar discursivamente o lixo no texto jornalístico, permite ao analista atravessar a literalidade do discurso, possibilitando criar "gestos de interpretação", que requer um distanciamento do sentido único, esgotável e homogêneo, isto significa dizer que o sentido de lixo é múltiplo, configura-se como lugar da "subjetividade", por isso o sentido de dejeto se diferencia conforme as diferentes formações discursivas dos distintos jornais.

$\mathrm{O}$ discurso configura-se como o material em que se tem acesso a ideologia pelo jogo da língua. No caso do texto jornalístico que trata da questão ambiental, torna-se possível analisar/compreender os sentidos que o termo lixo depreende nos recortes. Estes são significados por distintas formações discursivas; isto significa dizer que são constituídos por sujeitos ideológicos diferentes. 
Desse modo, desconstrói a concepção de que o sentido literal de lixo é apenas o estabelecido pela lei $\mathrm{n}^{\mathrm{o}}$ 7.862, de 19 de dezembro de 2002, sobre a Política Estadual de Resíduos Sólidos do Estado de Mato Grosso, definindo-o como “os que resultam das atividades humanas em sociedade e que se apresentem nos estados sólidos, semi-sólido ou líquido, este último quando não passível de tratamento convencional”; pois o sentido é (re) significado a partir dos diferentes sujeitos e se inscrevem na história. Conforme Orlandi (2007, p.147), “não há sentido sem interpretação, e a interpretação é um excelente observatório para trabalhar a relação historicamente determinada do sujeito com os sentidos, em um processo em que intervém o imaginário e que se desenvolve em determinadas situações sociais".

O sentido de lixo sempre poderá "a vir ser outros" (ORLANDI, 1995) pelo fato do sujeito se constituir e se significa entremeio aos fatores sócio-histórico-ideológico. O trabalho com o discurso permitiu compreender como a língua funciona, ver que os sentidos se movem por deslizamentos em diferentes condições de produção. No caso do lixo, pode-se perceber que cada texto jornalístico remete a diferentes situações. Dessa forma, o discurso faz pensar como a língua constrói o sentido e que este não está na literalidade das palavras, isto é, não se detém ao pré-construído, a opacidade da materialidade jornalística, mas sempre constituído em formações discursivas, E assim, se pode dizer dos efeitos de sentidos que um discurso produz.

\section{Referências}

BRASIL. Constituição da República Federativa do Brasil. Editora tecnoprint S.A.1988. (2010). Lei 12.305/2010 de Resíduos Sólidos. Lei de Resíduos Sólidos do Estado de Mato Grosso.

. (19 de dez de 2002). Lei n 7.862 , de 19 de dezembro de 2002. Lei de Resíduos Sólidos do Estado de Mato Grosso.

MARIANI, Bethania. O PCB e a imprensa: as conquistas no imaginário dos jornais 19221989. Campinas, SP. Ed. Da Unicamp, RJ, Ed. Revan, 1998.

MOTTA, Ana Luiza Artiaga Rodrigues da. O sujeito no discurso ecológico sobre a pesca na cidade de Cáceres Estado de Mato Grosso. Sínteses (UNICAMP. Impresso), v.9, p.255-264, 2004.

.A escrituração do Pantanal no discurso ambiental. In: Neuza Benedita da Silva Zattar, Ana Maria di Renzo. (Org.). Estudos da linguagem: Língua, sujeito e história. 1 ed. Campinas: Pontes, 2012, v.01, p.11-30. 
ORLANDI, Eni Puccinelli. Análise de discurso: princípios e procedimentos. Campinas, SP: Pontes, 1999.

Efeitos do verbal sobre o não verbal. Campinas, Revista Rua, n. 1, p. 35-47, 1995.

. Discurso e políticas públicas urbanas: A fabricação do consenso, Campinas: Editora RG, 2010.

PÊCHEUX, Michael. (1975). Semântica e discurso: uma crítica à afirmação do óbvio.Tradução de Eni P. Orlandi [et al.]. Campinas: Editora da UNICAMP, 1995.

SILVA, Telma Domingues da. A linguagem e a questão ambiental-representações políticas, cidadania e produção social. Entremeios, v 12, p. 129-142, 2016.

O sujeito urbano e a notícia impressa-novos percursos de leitura. Estudos linguísticos, São Paulo, v. 45, 2016.

Educação ambiental: a educação para o consumo na sociedade da informação.

Linguagem em (Dis) curso (Impresso), v. 11, p. 563-584, 2011. 